\title{
ADJUVANTS FOR APPLES: EFFECTS ON RUSSETING
}

\author{
R.E. GASKIN ${ }^{1}$, D.W.L. MANKTELOW ${ }^{2}$ and A. GEELEN ${ }^{3}$ \\ ${ }^{1}$ PPCNZ, PO Box 6282, Rotorua, New Zealand \\ ${ }^{2}$ Applied Research \& Technologies Ltd, PO Box 3415, Napier, New Zealand \\ ${ }^{3}$ Agrivet Services Ltd, PO Box 8734, Havelock North, New Zealand \\ Corresponding author: robyn.gaskin@ppcnz.co.nz
}

Fruit appearance is of critical importance in apples, but fruit rejected for russet make up a significant proportion of the crop each year. Nonylphenol ethoxylates have been the standard adjuvants in New Zealand for many years, but since their classification as endocrine disruptors, alternatives are needed for major export markets. Two studies in separate years established the russeting potential, in either dilute or concentrate sprays, of a range of adjuvants: alcohol ethoxylates (Actiwett, Chemwet 1000), pinolene polymers (Nu-Film-17, Sprayfast), polyalkoxylate/aliphatic alcohol blends (Regulaid, Spray Aid), an organosilicone/latex polymer blend (Bond Xtra), an organosilicone superspreader (Silwet L-77) and an organosilicone blend superspreader (Du-Wett). Both alcohol ethoxylates significantly increased russet, while no other adjuvant had any effects on export packout levels of the russet-sensitive varieties, Sciros (Pacific Rose ${ }^{\mathrm{TM}}$ ) and Sciearly (Pacific Beauty ${ }^{\mathrm{TM}}$ ). In the following year, concentrate sprays containing Du-Wett were compared with dilute spray programmes in four commercial orchards in different locations. Export packouts of $90-98 \%$ were achieved. The concentrate programmes reduced stem-end, cheek and total russet in two orchards. Fruit quality and the level of export grade fruit (cv. Tenroy (Royal Gala) and Braeburn) were not compromised by the use of Du-Wett adjuvant in concentrate spray programmes.

\section{RESISTANCE TO DICARBOXIMIDE AND BENZIMIDAZOLE FUNGICIDES IN BOTRYTIS CINEREA FROM GREENHOUSE TOMATOES IN NEW ZEALAND}

\author{
P.J. WRIGHT ${ }^{1}$, S. $\mathrm{CHNG}^{2}$, R.E. BEEVER ${ }^{3}$ and J. THOMPSON ${ }^{4}$ \\ ${ }^{1}$ Plant \& Food Research, Cronin Road, RD1, Pukekohe, New Zealand \\ ${ }^{2}$ Plant \& Food Research, Private Bag 4704, Christchurch, New Zealand \\ ${ }^{3}$ Landcare Research, Private Bag 92170, Auckland, New Zealand \\ ${ }^{4}$ BioForce, PO Box 812, Pukekohe, New Zealand
}

Corresponding author:wrightp@crop.cri.nz

Isolates from Botrytis cinerea collected from greenhouse tomato crops throughout New Zealand were tested for resistance to the dicarboximide fungicide vinclozolin and the benzimidazole fungicide carbendazim by assessing fungal growth on agar media amended with the fungicides (100 ppm active ingredient for both fungicides). Benzimidazoleresistant strains of $B$. cinerea were found on 15 of the 18 properties examined, and dicarboximide-resistant strains were found on 11 properties. Dicarboximide resistance was more prevalent in the Auckland region, with $71 \%$ of isolates resistant compared to $5 \%$ of isolates resistant for the other three regions. All of the strains that were resistant to dicarboximide were also resistant to benzimidazole. The high levels of dicarboximideresistant strains in the Auckland region correspond to reported loss of fungicide efficacy and loss of disease control in some greenhouses in this region. 